\title{
The Reform in Evaluation System as a Tool of Quality Improvement in Institute of Engineering
}

\author{
Bharat Raj Pahari ${ }^{1}$ \\ Institute of Engineering, Tribhuvan University, Pulchowk, Lalitpur, Nepal \\ Corresponding Email: brpahari@ioe.edu.np
}

\begin{abstract}
The present day notion is such that technology and technical education is treated as backbone of economy. Earlier understanding of education producing wisdom and building elite society has been changed; education is taken as the means of increasing productivity. This has demanded the quality engineering education that produces human resource capable enough to cope the growing need of the market and yield product of consumers' satisfaction. Institute of Engineering has established as an icon of quality engineering education in Nepal is putting its efforts in increasing its quality in the changing context. Though it is continuous process, IOE has applied some corrective measures to attain effective and efficient output in the institution. This paper is an attempt to shed light on the improvements in the evaluation system (examination) of IOE and analysis of the exam results.
\end{abstract}

\section{Introduction}

The Institute of Engineering (IOE) founded in 1930 (1987/11/19 BS) as the first technical school in Nepal and was reformed to the present shape in 1972 and has been producing the outstanding engineering technicians and engineers for more than 84 years. The tradition of excellence in the IOE is further intensified in the course of time. IOE has become more and more responsive to the ever-changing needs of students and the engineering profession. The IOE is recognized as Nepal's leading engineering institution.

IOE envisioned to become the center of excellence, both as think tank-premier national center of engineering education capable of addressing national engineering issues and as regional hub of south Asian center for research, innovation and dissemination of engineering knowledge. This is possible only by setting quality engineering education in the pioneer engineering areas relevant to nation and thereby enhancing national development process. It is true that quality is achieved only by creating excellence in work, work environment, human resources, etc.

The new world-order posed by globalization has set a challenge for capability and competency. The new paradigm is emerging; higher education has been accepted as capital- the source of knowledge and skill that eventually increases productivity. The global context is exposed more and more on the economic growth. It signifies that larger the accumulation of knowledge and skill, higher shall be the productivity and eventually higher economic growth. Technology has set new world order-global village. The tremendous technology development has left no sphere unless to consider for the quality of life. Understanding this fact, a new trend of 'global skill race' is on the way. The pace of technology and exceptional explosion of knowledge have made the higher education, particularly the engineering education, dynamic, as never before, constantly entering into uncharted areas. In order to carry on this responsibility, IOE has to be more

\footnotetext{
${ }^{1}$ Dean, Institute of Engineering, Tribhuvan University, Nepal
} 
responsive to the needs of the country and contribute to the quality in the field of engineering. The quality as it begins from the selection of competent students and faculties and depends on the curriculum, infrastructures and evaluation system.

\section{History of Engineering Education in Nepal}

The history of engineering education in Nepal can be traced to 1930, when a Technical Training School started with textile trade course and then after offering only trade courses and civil suboverseers programs. In 1959, this school was reorganized as the Nepal Engineering Institute, with the assistance of the government of India, and started offering civil overseer courses leading to a Diploma/ certificate level in Civil Engineering. The first batch of overseers was graduated in 1961. In the course of time Technical Training Institute was established in 1965 to cater growing need of technical human resource, with the assistance from the Government of Federal Republic of Germany, offered technician courses in General courses namely, General Mechanics, Auto Mechanics, Electrical Engineering and Mechanical Drafting. Nepal Engineering Institute was established 1959 with the assistance of the Government of India.

After the introduction National Education System Plan 1972, the then Nepal Engineering Institute at Pulchowk and the Technical Training Institute at Thapathali were brought under the jurisdiction of Tribhuvan University to constitute the IOE. In the course of time, Nepal government established purwanchal campus in Dharan in 1977 and paschimanchal campus in Pokhara in 1981 as the constituent campuses of IOE. The Nepal Engineering Institute and the Technical Training Institute were renamed as Pulchowk Campus and Thapathali Campus, respectively. Higher technical education started in the year 1978 with intake of 22 students in bachelor of Civil Engineering. Master's level education started in the year 1994 at IOE. There are 9 bachelor programs and 17 master programs running at present under IOE. Following the government policy, IOE has phased out the diploma program from 2011. The last batch of diploma shall graduate in the year 2015.

Besides constituent campuses, TU/IOE has affiliated colleges also. The first affiliation was awarded in 1998 and there are 10 affiliated colleges up to now.

\section{Evaluation system as an important quality parameter in Engineering Education}

Right from the beginning, it is customary that students are tested to know their level of knowledge in the university. The evaluation systems prevailing in IOE are internal assessment, tutorials tests, laboratory and other practical evaluation and final examinations.

The internal assessment has the weightage of $20 \%$ and teacher sets the process of assessment and submits the evaluation report to examination division. There is the practice that teacher takes formal internal assessment examination twice or multiple time and submits average or highest marks among them to the examination division. There is also the practice of internal evaluation through home assignments, report writing and viva -voce. Internal evaluations are interlinked with attendance also. Tutorials are other part of the internal evaluations. A part from the lecture classes tutorial classes are dedicated to make students familiar with practical problems. Students are assigned analytical problems to find solutions. Teacher assists student in the process. These are also the part of internal evaluations. 
Depending on the nature of the subjects and as described in the curriculum, there is the provision of internal laboratory/ practical marks. Students are given assignments and are solved within class hours. The marks are awarded to the works in the class. Such practical works bears the weightage of $25 \%$ to $50 \%$ as prescribed in the curriculum.

Final examinations are taken at the end of the semester. In general, it has the weightage of $80 \%$ and three hours written examinations are conducted in the final exam. The questions for the final exam are set by concerned teachers. These questions are moderated by senior teachers and finalized for the exam. The answer-sheets once collected are dispatched to concerned teachers for checking and marking. The duly checked and marked answer-sheets are collected and about $15 \%$ sheets are scrutinized before tabulation and preparation for result. Exam board finally announces the result.

\section{Improvement measures applied in IOE}

The evaluation system is in fact the strong tool to attain quality. This is an indicator of students competency in the subject matter. Owing to the voices in the IOE on the evaluation system, different measures were taken for the improvement in the evaluation system in the IOE. Time and again the question setting and moderation were asked to make them effective.

\subsection{Curriculum revision}

It is a regular work to revise prevailing curriculum in every academic institution. Despite many attempts, IOE was not able to revise the coursed for long time. This task was given high priority and as a result of this all curricula in all discipline were revised in 2011. The evaluation grid has been specified in the revised curriculum. Following this evaluation grid, the questions are made uniform covering all chapters in the course. The format of the question has been made uniform.

\subsection{Academic calendar}

The academic calendar is the true mirror of the quality of the education. The quality issue is always associated with academic calendar. Since many years, the academic calendar was not prepared in the IOE. Most of the time, the class and exam routine were shifting. Different interest groups used to influence exam routine. This has resulted four years bachelor course to be finished in five years or even more period. Visualizing this dilemma, IOE set five year academic calendar with milestones dates and strictly followed implementation. Every student can now see dates of curricular and extracurricular activities including class days and vacations. The milestones of internal and external exams and tutorial dates are all indicated in the calendar. Despite some resistance the calendar has been strictly in action. IOE has set academic calendar for coming 5 years. The flexibility of exam schedule and delaying of result cannot be imagined in IOE now. Results are announced within one month of the last day of exam. This has improved the results in the examination.

Teachers were asked to rate their feeling and observations regarding the steps taken by the IOE towards strict implementation of academic calendar and setting admission criteria and procedure, the percent of the teachers who strongly agreed were $60 \%$ and agreed were $37 \%$ totaling $97 \%$. This is the overwhelming positive response. 


\subsection{Examination system}

This is true that one of the indicators of the quality is the exam result. The whole process of the exam system- right from the question settings to checking of the answer sheet is responsible for the good results. The first step of improving exam is the question setting. The question setting process has been well specified in the evaluation grid developed in the curriculum revision. Besides, the provision of setting three sets of questions has been made mandatory. The moderation process is done by drawing one set out of three sets of questions. Attention is given to cover all the chapters of the subjects as indicated in the evaluation grid. Rule has been developed for checking of the answer-sheets. The faculties having more than five years of experience are entitled to be involved in the checking process. The examination system has been strengthened by setting clear evaluation scheme in the curricular. The pattern of questions, the coverage and weightage of the chapters into the questions and the marks allotted to the question are all set. The emotional reactions of the teachers in the question setting and checking of the answer sheet etc. are now controlled to the larger extent. The system of chance exam, sometime called make up exam also, has been introduced. This exam is conducted within three months of final exam. Those students not passed in the final exam by any reason may appear in this exam. Students have largely benefited with this exam. The knowledge content of the student gained during the preparation in final exam that will be retained till these three months and exist possibility of succeeding in to the make-up exam. Student have largely benefitted from this policy and pass rate has been increasing.

\subsection{Entrance examination}

The entrance exam of IOE is regarded as excellent calibration test and proved itself as one of the outstanding example of fair exam in Nepal. IOE conduct entrance exam for bachelor and master program. Before the phase out of the diploma, there was also the entrance exam for diploma program as well. The entrance exam is conducted by sovereign exam board following precise regulations. The procedure of the exam was such that questions are set by well experienced professors, generally not involved in the plus two colleges. There set of questions are moderated in to one set by professors other than setters. This set in developed into three sets in such a way that their sequential order is changed, but the questions are same and numbers of question remain same. The seating patterns are well defined and every student is given predefined seat. The neighboring students have question with different order and sequence. The students have to undergo through body checking. Even the mobile phone and purse cannot be carried during exam.

The credibility of the entrance exam has been established basically by the transparent procedures, strong and dedicated exam board, strict examination, answer sheets template evaluated by software; result in coded languages, etc. IOE has managed to provide detailed information regarding the application procedures and entrance test through its website. Students are provided information regarding the subjects for examination, course content, marking system, sample test. The results are published in website. IOE prepares handbook on entrance examination indicating exam policy and regulations.

The minimum requirements for admission to the under graduate courses in the Campuses of IOE are: completion of Intermediate of Science (Physical Group with Physics, Chemistry, Mathematics) or equivalent course recognized by the TU; passed in Diploma in Engineering or 
equivalent, A-level with physics chemistry and mathematics. In all cases, students should have scored at least $50 \%$ of the total marks in aggregate: and pass the entrance admission tests conducted by IOE. This exam is the national competitive exam.

Among the students who applied for entrance test at Bachelors' level, $48.81 \%$ and $61.84 \%$ passed in 2012 and 2013, respectively. Among the females, 49.52\% in 2012 and $47.44 \%$ in 2013 passed the entrance tests. However, regarding those who passed the entrance test and applied for admission $31.2 \%$ passed in total and $45.89 \%$ females passed in 2012. Similarly among those who passed entrance test and applied for admission, 19.28\% passed in total while among females $31.97 \%$ passed in 2013 . The data thus clearly showed that though the pass percent of the total students and female was higher, the number who applied later for admission was relatively low in both years 2012 and 2013. Exceptionally, about one third of the students only applied for admission in the year 2013. Compared to male students more females (31.97\%) applied for admission in 2013.this has indicated competitiveness of the student in the exam.

\subsection{Orientations of Teachers}

Teachers are the main source of making uniform the evaluation system. Time and again, emotional behaviors of teachers were manifested and student's complains were appearing. Such impression used to be reflected in the exam results. There were also the cases that teachers are not aware of examination system- formulation of questions, moderation and evaluation of the students' works. Orientation of teachers was thought to correct such subjective judgments. Periodic interactions and seminars are being organized before the semester start. This has given consistency in questions patterns and results.

\section{Results findings after the application of corrective measures}

The results of the exams are one indicator to identify the quality of the education. The curricula revisions and other corrective measures applied are also in larger extent reflected in the exam results. The worldwide trend of evaluation as indicated in the literature was found to measure collectively final and make-up exam results. The combined exam results of final and makeup(chance exam) exam were analyzed to find the trend of pass rate in all campuses and colleges under IOE. This was analyzed in all semester with new revised courses.

The revised curriculum was applied in the first year first part of 2066, 2067, 2068 and 2069 batches and their results are published. The corrective measures were taken in the exam system. Conduction of exams was done in a more effective way. The questions were made uniform with course. Checking of answer sheets were made more consistent. All these measures indicated substantial impact in to the quality of students and their pass rates (exam records, IOE 2070).

The central campus Pulchowk, though, used to have good results, after the corrective measures, the result of the campus in all programs is found stable. This can be visualized in the table below: 


\begin{tabular}{|c|c|c|c|c|c|c|}
\hline \multicolumn{7}{|c|}{ Central Campus Pulchowk, First year first part } \\
\hline Campus & Level & Program & 2066Batch & 2067Batch & 2068Batch & 2069Batch \\
\hline PUL & BE & BLEX & 85.42 & 89.58 & 93.75 & 87.5 \\
\hline PUL & BE & CIVL & 95.14 & 97.22 & 95.79 & 92.71 \\
\hline PUL & BE & COMP & 85.42 & 95.83 & 87.5 & 95.83 \\
\hline PUL & BE & ELEC & 85.42 & 91.49 & 91.67 & 85.42 \\
\hline PUL & BE & MECH & 87.5 & 93.75 & 91.67 & 91.67 \\
\hline PUL & BE & ARCH & 62.5 & 83.33 & 89.58 & 85.42 \\
\hline
\end{tabular}

Above table gives the pass rate in different bachelor programs. The results in the 067, 068 are relatively increasing in comparison to 066 batch. The 069 batch is having better result than 066 batch; however it is in the border compared to other batches.

The graphs drawn from the table shows that in central campus pulchowk the results are varying from 85 to 100 percent. The result of the architecture group has been increasing after the course revision.

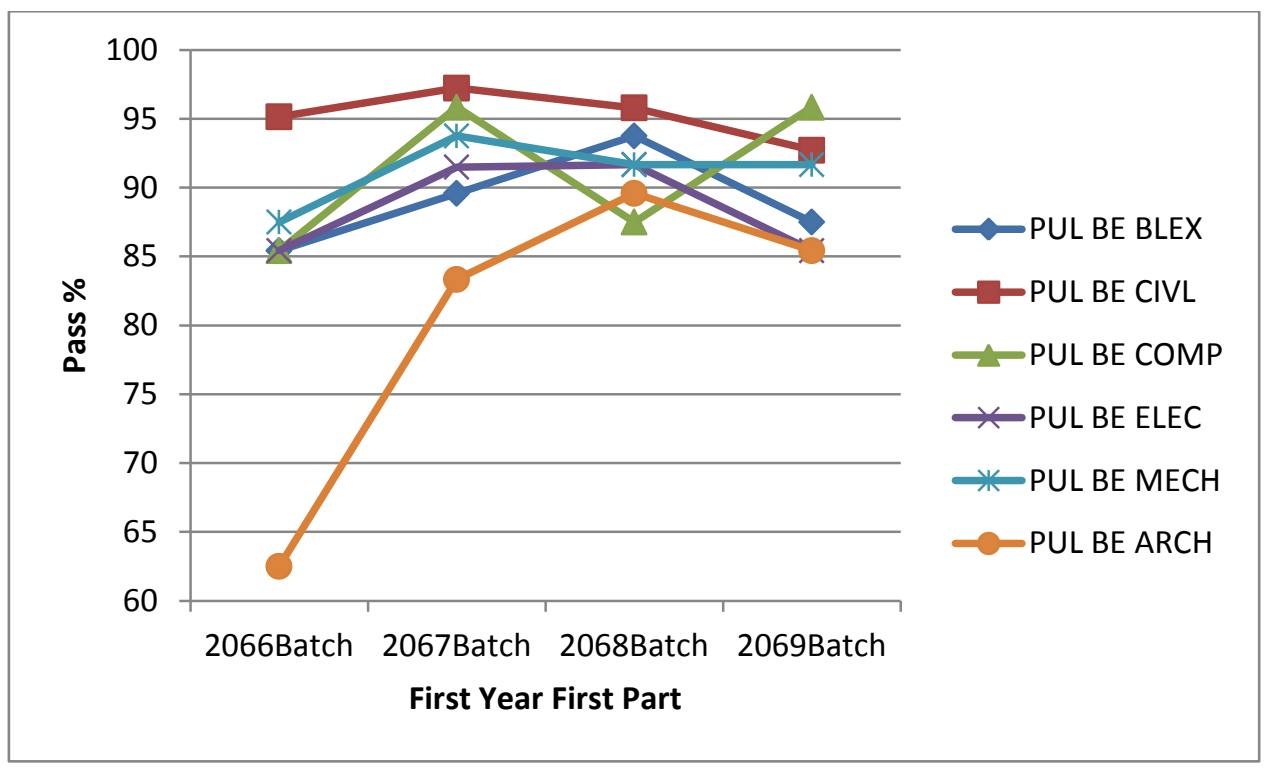

The case of Thapathali campus is presented in the table below. The results are a bit disappointing. The pass rates are decreasing in all programs. The question is whether this is due to the corrective measures or from any other reason. 


\begin{tabular}{|c|c|c|c|c|c|c|}
\hline \multicolumn{7}{|c|}{ Thapathali Campus, First year first part } \\
\hline Campus & Level & Program & 2066Batch & 2067Batch & 2068Batch & 2069Batch \\
\hline THA & BE & BLEX & & 80.43 & 42.55 & 61.7 \\
\hline THA & BE & CIVL & 81.25 & 85.11 & 75 & 81.05 \\
\hline THA & BE & INDU & 12.5 & 38.3 & 37.5 & 27.66 \\
\hline THA & BE & MECH & & & 81.25 & 79.17 \\
\hline
\end{tabular}

The results of civil and mechanical are relatively stable, but the electronics and industrial engineering are decreasing. This can be visualized in the graphs below. After observing the objective condition of the campus, this can be said that the unrest undergoing inside the campus has reflected into the results of the exam. The environment in the campus is not found conducive for teaching learning. There were frequent clashes between students, repeated pad lucks and picketing of teachers. This is exceptional case.

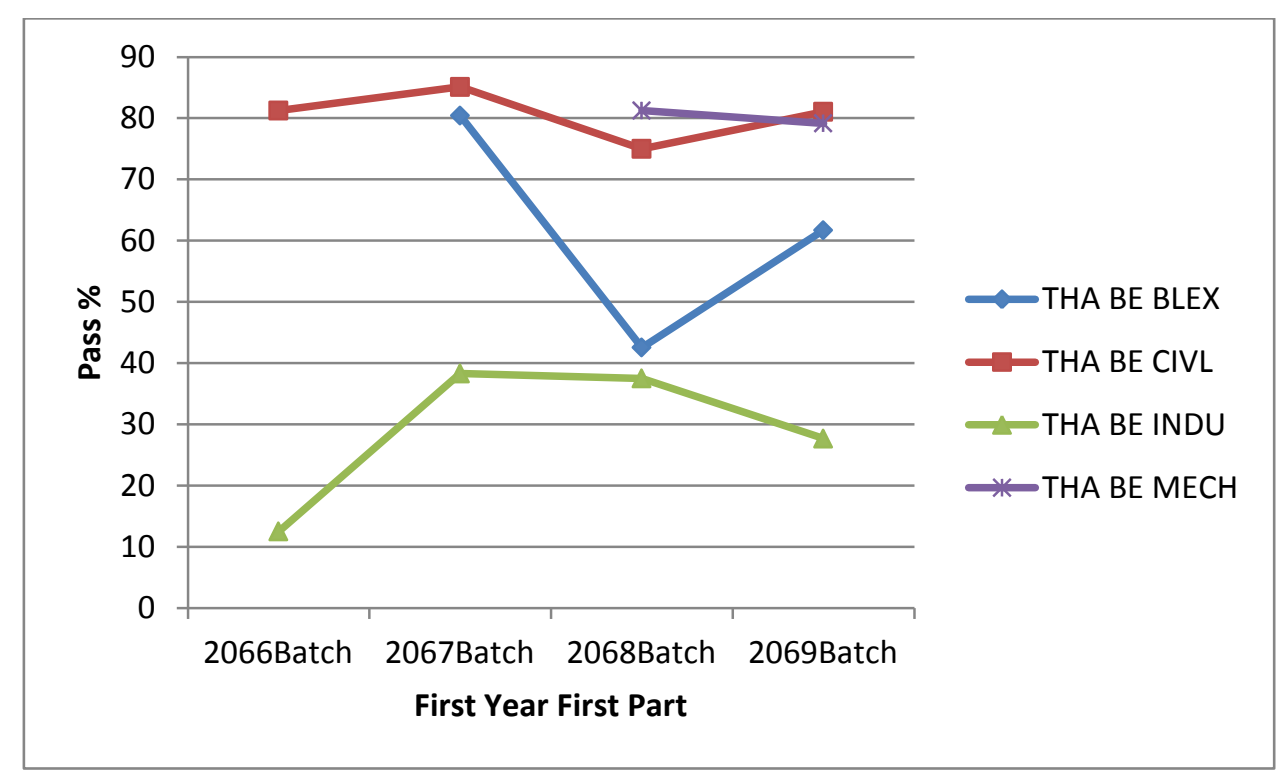

The results in the paschimanchal campus are increasing in all programs. Civil program has encouraging result which is comparable with central campus pulchowk. The result of mechanical program, though it is newly introduced, has the pass rate approaching $80 \%$. The pass rates are indicated in the table below. 


\begin{tabular}{|c|c|c|c|c|c|c|}
\hline \multicolumn{7}{|c|}{ Paschimanchal campus, First year first part } \\
\hline Campus & Level & Program & 2066Batch & 2067Batch & 2068Batch & 2069Batch \\
\hline WRC & BE & BLEX & 58.33 & 48.94 & 60.42 & 62.5 \\
\hline WRC & BE & CIVL & 77.08 & 80.21 & 87.5 & 90.63 \\
\hline WRC & BE & COMP & & & & 43.75 \\
\hline WRC & BE & ELEC & & 40.43 & 76.6 & 77.08 \\
\hline WRC & BE & GEOM & & & & 47.92 \\
\hline WRC & BE & MECH & & & & 79.17 \\
\hline
\end{tabular}

The geomatics program is new subject recently introduced in IOE. This program has only about $48 \%$ pass rate in the first year first part of the 069 batch. The result of the computer program is also about $44 \%$ which is not encouraging. The graph of other three programs (civil/electronics/ electrical) shows increasing pass rates.

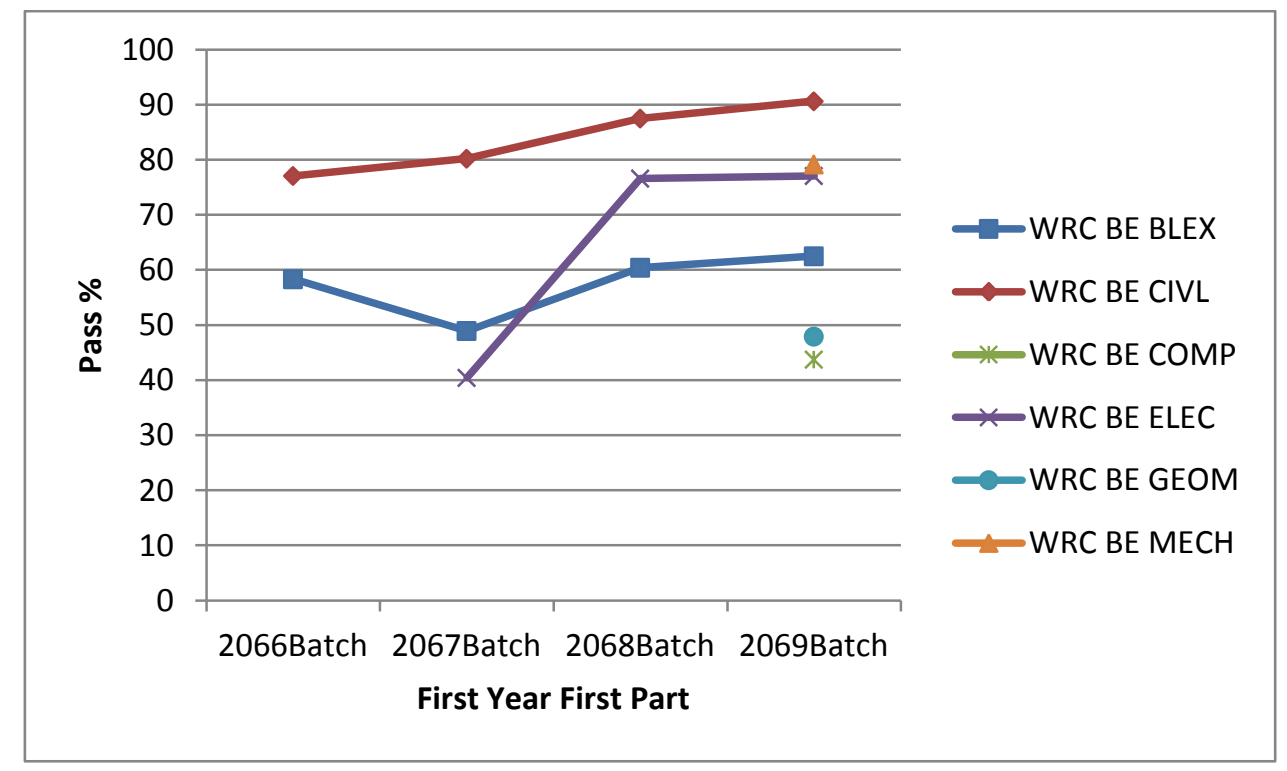

Three programs were introduced in 2069. The results of computer and electronics are not encouraging however other results are increasing comparing to part condition.

\begin{tabular}{|c|c|c|c|c|c|c|}
\hline \multicolumn{7}{|c|}{ Purwanchal Campus, First year first part } \\
\hline Campus & Level & Program & 2066Batch & 2067Batch & 2068Batch & 2069Batch \\
\hline ERC & BE & AGRI & 29.17 & 16.67 & 39.58 & 39.58 \\
\hline ERC & BE & BLEX & & & & 31.25 \\
\hline ERC & BE & CIVL & 62.5 & 52.08 & 70.83 & 77.08 \\
\hline ERC & BE & COMP & & & & 31.25 \\
\hline ERC & BE & MECH & & & & 68.75 \\
\hline
\end{tabular}


The graph shows decreasing result in 2067 batch and then after increasing trend of pass rates.

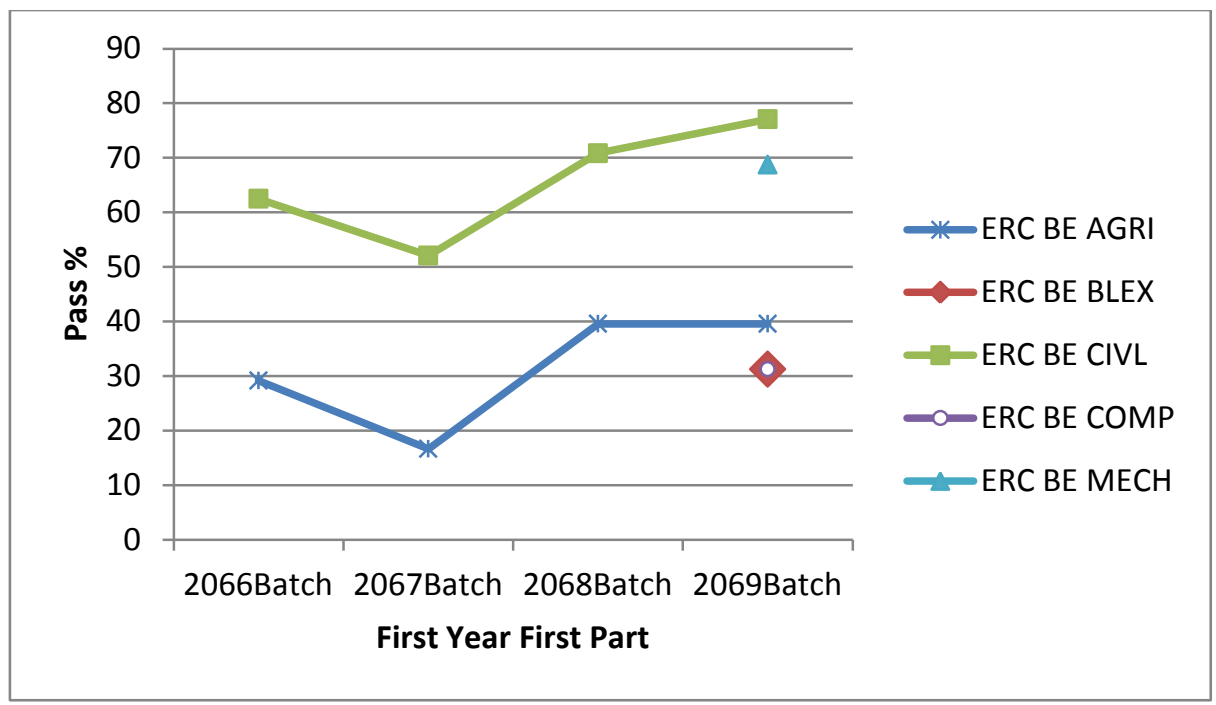

The results in all constituent campuses in all programs show increasing trend in the pass rates except in Thapathali campus. This shows improvements have yield quality into the IOE.

Similar trends are seen in the results of the affiliated colleges.

Following table indicates the cumulative pass rates of advanced college. It shows increasing range in all programs. The result in civil program is encouraging.

\begin{tabular}{|c|c|c|c|c|c|c|}
\hline \multicolumn{7}{|c|}{ Advanced college, first year first part } \\
\hline College & level & program & 2066Batch & 2067Batch & 2068Batch & 2069Batch \\
\hline ADC & BE & BLEX & 25.88 & 39.68 & 46.59 & 29.27 \\
\hline ADC & BE & CIVL & 62.2 & 63.54 & 77.5 & 79.17 \\
\hline ADC & BE & COMP & 23.75 & 28.21 & 31.17 & 39.53 \\
\hline ADC & BE & ELEC & 17.5 & 32.5 & 60 & 52.5 \\
\hline
\end{tabular}

The results of himalaya college is also achieving increasing trends in all programs. This is indicated in the table below.

\begin{tabular}{|c|c|c|c|c|c|c|}
\hline \multicolumn{7}{|c|}{ Himalaya college, first year first part } \\
\hline College & Level & Program & 2066Batch & 2067Batch & 2068Batch & 2069Batch \\
\hline HEC & BE & BLEX & 14.58 & 28.57 & 22.92 & 38.64 \\
\hline HEC & BE & CIVL & 61.46 & 54.17 & 80 & 82.29 \\
\hline HEC & BE & COMP & 27.27 & 31.58 & 24.19 & 22.45 \\
\hline HEC & BE & ARCH & 29.17 & 50 & 66.67 & 50 \\
\hline
\end{tabular}


This table shows encouraging result in the civil programs, whereas results are increasing in other programs.

The cumulative results of Kantipur college in all programs are shown in the table below. The pass percentage of civil program is increasing, whereas in other programs, results are stable.

\begin{tabular}{|c|c|c|c|c|c|c|}
\hline \multicolumn{7}{|c|}{ Kantipur college, first year first part } \\
\hline College & Level & Program & 2066 Batch & 2067Batch & 2068Batch & 2069Batch \\
\hline KAN & BE & BLEX & 32.56 & 38.55 & 36.51 & 25 \\
\hline KAN & BE & CIVL & 51.14 & 53.41 & 67.82 & 77.27 \\
\hline KAN & BE & COMP & 32.77 & 31.91 & 22.62 & 27.4 \\
\hline
\end{tabular}

The results in the electronics and computer are not following increasing trends. This has demanded the role of teachers and management of the college.

Following table shows the students' pass percentage of Khopwa College at Bhaktapur. The results are following increasing trends in both civil and electrical programs.

\begin{tabular}{|c|c|c|c|c|c|c|}
\hline \multicolumn{7}{|c|}{ Khopa college, first year first part } \\
\hline College & Level & Program & 2066Batch & 2067Batch & 2068Batch & 2069Batch \\
\hline KCE & BE & CIVL & 57.29 & 57.29 & 88.54 & 85.26 \\
\hline KCE & BE & ELEC & 36.17 & 54.17 & 52.08 & 64.58 \\
\hline
\end{tabular}

The table below indicates the cumulative pass results of the katford college. The results in the 067 and 068 batches are found increasing; however the result of 069 is slightly decreasing. This may be due to unrest and vandalism occurred in the college during 069. However, the cumulative pass rate is higher compare to previous results.

\begin{tabular}{|c|c|c|c|c|c|c|}
\hline \multicolumn{7}{|c|}{ Katford college, first year first part } \\
\hline college & level & program & 2066Batch & 2067Batch & 2068Batch & 2069Batch \\
\hline KIC & BE & BLEX & 21.28 & 21.21 & 20 & 18.18 \\
\hline KIC & BE & CIVL & 31.25 & 43.59 & 46.25 & 37.97 \\
\hline KIC & BE & COMP & 19.15 & 37.04 & 26.09 & 23.81 \\
\hline
\end{tabular}

The table below indicates the cumulative pass rate results of the Kathmandu college. The results are not increasing in the 067 and 068 batches, however results of 069 batch is increasing. The results of civil and architecture are encouraging. 


\begin{tabular}{|c|c|c|c|c|c|c|}
\hline \multicolumn{7}{|c|}{ Kathmandu college, first year first part } \\
\hline college & level & program & 2066Batch & 2067Batch & 2068Batch & 2069Batch \\
\hline KTH & BE & BLEX & 39.23 & 48.44 & 45.31 & 33.88 \\
\hline KTH & BE & CIVL & 67.77 & 63.64 & 70.83 & 71.07 \\
\hline KTH & BE & COMP & 44.83 & 32.18 & 35.63 & 37.93 \\
\hline KTH & BE & ELEC & 54.55 & 34.88 & 31.82 & 47.73 \\
\hline KTH & BE & ARCH & 83.64 & 72.22 & 80 & 82.69 \\
\hline
\end{tabular}

The result indicates that some efforts of the management need to be made to correct the causes of poor results.

Following table shows the results of the lalitpur college. This college has a single civil program and the results are in increasing order.

\begin{tabular}{|c|c|c|c|c|c|c|}
\hline \multicolumn{7}{|c|}{ Lalitpur college, first year first part } \\
\hline college & level & program & 2066Batch & 2067Batch & 2068Batch & 2069Batch \\
\hline LEC & BE & CIVL & & 41.67 & 52.08 & 64.58 \\
\hline
\end{tabular}

The table below indicates the cumulative pass results of national college. The results are following increasing trends in all four programs. The result of civil program is encouraging.

\begin{tabular}{|c|c|c|c|c|c|c|}
\hline \multicolumn{7}{|c|}{ National college, first year first part } \\
\hline college & level & program & 2066Batch & 2067Batch & 2068Batch & 2069Batch \\
\hline NAT & BE & BLEX & 21.57 & 43.75 & 39.13 & 34.78 \\
\hline NAT & BE & CIVL & 26.04 & 40.63 & 62.11 & 71.88 \\
\hline NAT & BE & COMP & 35.42 & 26.09 & 39.13 & 39.29 \\
\hline NAT & BE & ELEC & 18.18 & 35.56 & 29.17 & 31.25 \\
\hline
\end{tabular}

The table below shows the pass rate of first year first part of the Sagarmatha college. The result of civil program is encouraging and in the increasing trends. The result in the electronics in 068 batch is not satisfactory, however the result of 069 batch is following increasing trend.

\begin{tabular}{|c|c|c|c|c|c|c|}
\hline \multicolumn{7}{|c|}{ Sagarmatha college, first year first part } \\
\hline college & level & program & 2066Batch & 2067Batch & 2068Batch & 2069Batch \\
\hline SEC & BE & BLEX & & 55.56 & 31.91 & 50 \\
\hline SEC & BE & CIVL & & 68.75 & 87.5 & 89.58 \\
\hline
\end{tabular}

Following table shows the students' cumulative pass results in Janakpur College. The results of the civil program found increasing in the 067 and 068 batches however slightly decreased in the 
069 batch. This may be due to unrest and vandalism in the college and impair of academic environment. The result of the electronics is following increasing trend.

\begin{tabular}{|c|c|c|c|c|c|c|}
\hline \multicolumn{7}{|c|}{ Janakpur college, first year first part } \\
\hline college & level & program & 2066Batch & 2067Batch & 2068Batch & 2069Batch \\
\hline JAN & BE & BLEX & 14.81 & 27.59 & & \\
\hline JAN & BE & CIVL & 27.36 & 34.88 & 39.58 & 20 \\
\hline JAN & BE & COMP & & & 15.38 & \\
\hline
\end{tabular}

\section{Conclusions}

The corrective measures are the tools to achieve quality of engineering education. The situation was such that even the regular works were not taking place during past decade in the academic institution. This had brought sedentary states in IOE. There was a need to put some efforts to bring momentum into the institution. The political unrest prevailing in the country was the instrument for the inactive role of institutions. Time and again, many efforts were made in the revision of courses in the last decades; however the conventional attitudes prevailing within the institute were causing obstructions in the revision process. Despite this condition, additional efforts were made and team building was given priority in order to complete the course revision process. Even though, it took three years to complete the course revision process. This process is over and course revision of all years of all programs is completed in 2012.

The other burning fact putting impact in the IOE is the emotional reactions of students, teacher and staffs. These reactions were casing obstructions in the academic and administrative delivery eventually making calendar uncertain. There were questions on the dates of exams, class routines, etc. The four years duration of academic programs were sometime completing on more than four years. Visualizing this fact, strict administrative measures were taken and academic calendar was set for 5 years. The calendar shows milestones of exam dates, class start and completion, vacations, class days, other holidays, etc. There were mild resistances at the beginning, however it was subsided eventually assured and stable calendar has been developed in 2010. This well defined calendar has developed new academic environment and confidence among the stakeholders within IOE.

It is normally understood the evaluation system as the mirror of the quality of the institution. Right from the beginning, IOE had trustworthy exam system. However, there were voices of discrepancies. Thorough analysis on the evaluation process was done and corrective measures were undertaken. The mode of question setting and moderation were brought into an order. The checking of answer-sheets was harmonized and made more concrete for the uniformity and timely results. The scrutinizing process was made more effective to ensure consistent results. Faculties were made more responsible in the evaluation process. The last attempt is the setting of the evaluation scheme of every subject in all years and parts of the programs. This scheme has defined the questions numbers, chapters and marks within given question-grid. This has insured the question- setting within the chapters. There were strong voices of students and faculties to revisit on the examination and results. Visualizing this, discussions were made with in stakeholders on the serious impact of performances of students and faculties on the exam results. 
The prevailing practices around the world were considered. The effective practice of make-up exam has been introduced. The make-up exam is taken just after the final exam for those who are unsuccessful in the final exam. The indicators are appearing such that students pass rates are increasing and confidence level of students and faculties is growing.

The cumulative results of the first year first part have been taken as the indicators and this is a true mirror of all campuses and colleges of increasing their pass rates. Similar trends are seen in all years and parts in the bachelor level. This has insured the increase of quality of engineering education in IOE.

\section{References}

[1] History of Institute of Engineering: http://www.ioe.edu.np

[2] Strategic plan (2011-2015) of institute of engineering, 2011.

[3] IOE exam results of different batches from 2066 to 2069 batches. 